\title{
Female copulation calls vary with male ejaculation in captive olive baboons
}

\author{
Stefano Vaglio ${ }^{\mathrm{a}, \mathrm{b}, *}$, Louise Ducroix ${ }^{\mathrm{b}}$, Maria Rodriguez Villanueva ${ }^{\mathrm{b}}$, \\ Rosanna Consiglio $^{\mathrm{b}}$, Ayong Julia Kim ${ }^{\mathrm{b}}$, Patrick Neilands ${ }^{\mathrm{b}}$, \\ Kerstin Stucky $^{\mathrm{b}}$ and Adriano R. Lameira ${ }^{\mathrm{c}}$ \\ ${ }^{a}$ Department of Biology, Chemistry and Forensic Science, University of Wolverhampton, \\ Wolverhampton, UK \\ ${ }^{\mathrm{b}}$ Department of Anthropology \& Behaviour, Ecology and Evolution Research (BEER) \\ Centre, Durham University, Durham, UK \\ ${ }^{c}$ Department of Psychology, University of Warwick, Coventry, UK \\ *Corresponding author's e-mail address: S.Vaglio@wlv.ac.uk
}

Received 16 September 2019; initial decision 12 November 2019; revised 18 July 2020; accepted 21 July 2020; published online 11 August 2020

\begin{abstract}
Copulation calls are mating-associated vocalizations that are common in primates, with females vocalizing after copulation in several Old World monkeys and apes. Baboon females typically produce copulation calls that correlate with fertile phase. Calls are, thus, regarded as an upshot of cycle physiology and sexually selected calls. Here, we describe three captive troops of olive baboons wherein, against expectation, females suppressed vocalizing during copulations. Vaginal cytology, together with sexual swelling observations, confirmed that females experienced full receptive cycles. Ovulation did not affect vocal probability during sex, while copulation calls were predicted by male ejaculation just as in other Old World primate species. Results cast doubt on the existence of physiological triggers for baboon copulation calls. Social factors may instead play a larger role. Alterations in social structure (as typically observed in the wild) may be implemented strategically as captive enrichment in order to reveal how females in highly social primates change sexual strategies and, therefore, the use of their copulation calls.
\end{abstract}

\section{Keywords}

copulation calls, vaginal cytology, vocal context learning, Papio anubis. 


\section{Introduction}

Copulation calls are species specific, easily distinguishable vocalizations given before, during or after mating. They occur in a wide range of animal species, from Northern elephant seals (Cox \& LeBoeuf, 1977) to little brown bats (Racey et al., 1987), peacocks (Anoop \& Yorzinski, 2013) and several primate species (Hamilton \& Arrowood, 1978).

Non-primate animals usually emit calls before copulation to advertise sexual receptivity. These 'mating calls' are a sexually selected trait, primarily used by males to attract female mates (reviewed in Fedorka \& Mousseau, 2001) and advertise the male mating success (e.g., mice - White et al., 1998). Females use copulation calls to incite mate guarding behaviour in the male mates (e.g., African elephants - Poole et al., 1988; Poole, 1989) and to prevent or end unwanted copulations by attracting another high-ranking male (e.g., fowls - Pizzari, 2001; Løvlie et al., 2014).

Primates produce vocalizations towards the end or right after copulation. These 'copulatory calls' are sexually selected and highly variable across the primate order (reviewed in Dixson, 1998); for instance, both the relative occurrence of vocalizations during/after copulation and the form of the call vary depending on the primate species, while the structural complexity of calls depends on the species promiscuity and therefore different needs of female self-advertisement (Hamilton \& Arrowood, 1978). Although their function still remains unclear, primate copulation calls are thought to signal sexual receptivity and thus affect mate choice. They would play a crucial role in increasing mate guarding by the consort male and encouraging mating attempts by other males (Pradhan et al., 2006). In particular, female copulation calls would be a form of post-copulatory female choice evolved under the selective pressures of risk of infanticide and sperm competition (Maestripieri $\&$ Roney, 2005).

Female baboons advertise their ovulation publicly through anogenital swellings that offer striking visual sexual signals (Darwin, 1876). Copulation calls in baboons are typically produced by females in oestrus (e.g., gelada baboons - Moos Heilen \& Sossinka, 1990; yellow baboons - Semple, 2001) and predominantly in consortships during the ovulation phase of their cycle (e.g., yellow baboons - Semple et al., 2002; Guinea baboons Maestripieri et al., 2005). These calls presumably advertise sexual receptivity, and promote sperm competition in order to reduce the risk of infanticide and obtain 'good genes' for their male offspring (O'Connell \& Cowlishaw, 
1994). Accordingly, baboon copulation calls are viewed as sexually selected calls elicited physiologically (reviewed in Pradhan et al., 2006) while little is known about the importance of social mediators. Copulation calls may be under different selective pressures depending on the species in question, even within the same genus. For instance, baboon species vary significantly in terms of social variables that may drive their reproductive strategies; thus, baboon copulation calls may be more or less socially mediated depending on the species of genus Papio.

Two lines of evidence cast doubt, however, on the current assumptions about the physiological mechanisms and sexual selective forces that underpin the use of copulation calls by female baboons.

First, the use of copulation calls in several Old World monkeys, great apes and even humans does not follow the ovulation cycle (Nikitopoulos et al., 2004; Pfefferle et al., 2008; Townsend et al., 2008, 2011; Clay \& Zuberbuhler, 2011; Clay et al., 2011; Engelhardt et al., 2011; Townsend \& Zuberbuhler, 2014). Instead, females seem to use these calls strategically, where voluntary control over when to produce copulation calls is presumed necessary (Nikitopoulos et al., 2004; Pfefferle et al., 2008; Townsend et al., 2008, 2011; Clay \& Zuberbuhler, 2011; Clay et al., 2011; Engelhardt et al., 2011; Townsend \& Zuberbuhler, 2014) — a capacity that classifies as vocal context learning (Janik \& Slater, 1997). However, these Old World primate species advertise ovulation through visual sexual anogenital swellings, like baboons; which indicates no obligatory connection between anogenital swelling physiology and copulation calls in primates. Therefore, reassessment of the presumed mechanisms underpinning vocal sexual signals in baboons is advisable.

Second, female baboons are known to be able to strategically use contact calls (Silk et al., 2016). If vocal context learning applies to the female baboon's social call repertoire, with the respective underpinning neuro-motor connections being in place, there are few reasons to expect that usage control would not operate over other social calls, namely, copulation calls. These open questions carry empirical, and potentially translational, implications regarding how we understand female baboons' reproductive physiology. To address these questions, we tested the presumed causal relationship between the course of the sexual cycle in female baboons and their use of copulation calls. We focused on three troops of captive olive baboons. Notably, contrary to what has been observed in baboons (Moos Heilen \& Sossinka, 
1990; Henzi, 1996; Semple, 2001; Semple et al., 2002; Maestripieri et al., 2005; Nitsch et al., 2011), females habitually remained silent during sexual activity, providing a unique opportunity to investigate, non-invasively, the presumed connection between ovulation and copulation call usage in female baboons. We tested the two competing hypotheses about the mechanisms underpinning female baboon vocal behaviour during sex by using a generalized linear mixed model: whether ovulation phase (physiological predictor) or male mounting (social predictor) played a predominant role eliciting copulation calls in our captive population of female baboons. We used vaginal cytology, together with behavioural observations, to estimate the ovulation phase; we chose the mounting outcome, and did not include any other alternative social predictor variables, due to the limitations of this sample of captive baboons (i.e., all females and males were sexually mature adults; all females were regularly cycling; no females were pregnant or lactating; all males were vasectomised; we could not establish the male rank between males living in different one-male multi-female troops; group composition and husbandry conditions were comparable across the troops).

\section{Material and methods}

\subsection{Study subjects and housing}

We investigated 34 adult females with regular menstrual cycles, housed at the Station de Primatologie (SdP), Centre National de la Recherche Scientifique (CNRS), Rousset-sur-Arc (France), aged between 4.5 and 24.5 years at the beginning of the study. Wild female olive baboons experience menarche at 4 years, are considered sexually mature at 4.5 years old and first conceive at approximately 5 years old (reviewed by Honoré \& Tardif, 2009). Colonyreared baboons show menarche up to a year earlier and a slightly shortened time between menarche and first conception (reviewed by Honoré \& Tardif, 2009). Unpublished data from the Station de Primatologie confirmed that females reach sexual maturity around 3.5 years in this captive population (Romain Lacoste, personal communication).

The subjects were divided into four troops. Three test troops consisted of six females and one male (Troop 1), three females and one male (Troop 2), and five females and one male (Troop 3), respectively. These three onemale multi-female troops lived in neighbouring enclosures, with permanent fences separating the troops but still allowing females to have access also to 
the males living in other groups (i.e., this included sexual presentations and interactions but, if compared to access to the male within their own group, we recognize that females could not have full access to neighbouring males). Twenty females living without a male in the group comprised the control troop. Samples were collected for two females in each one-male group (i.e., six in total) and for six females in the multi-female control troop. During the study period all females did not receive contraception and were neither pregnant nor lactating. All males were vasectomised, but this did not affect their sexual behaviour since this procedure does not remove the gonads, which remain active.

\subsection{Training}

Before data collection, females were trained to present their sexual swelling allowing the collection of vaginal secretions (i.e., genital cytology sampling) for 10 weeks using positive reinforcement training.

\subsection{Behavioural data collection}

We collected behavioural data on a daily basis, six days per week, for four months for each female via 30-min continuous focal animal sampling, using pen and paper (clipboard, check sheets, timer). We measured male sexual interest by recording all occurrences of inspections, mate-guarding and copulations, along with the direction of behaviour where appropriate, and the identity of the male involved. In particular, mate-guarding is an easily observed, unambiguous behavior, where a male maintains close spatial proximity to the female (i.e., a female within arms' reach of the male), and monitors her continuously (Alberts et al., 2003). We also estimated the proximity of each female to all males (noting which female was within arms' reach of which male) every $2 \mathrm{~min}$, to determine how much time each male had close access to the female. However, although females had access also to males living in neighbouring enclosures, including sexual presentations and interactions with them, we recognize that the presence of permanent fences separating these troops had significant implications for the significance of factors like mate-guarding behaviour by males or proximity of each female to all males.

During focal animal sampling, we recorded social behaviours between focal females and males (e.g., when a female was grooming or being groomed). 
Concerning sexual behaviours, we recorded behavioural indicators of proceptivity (Beach, 1976; Campbell, 2007). Proceptivity refers to sexual behaviours displayed by females toward males to indicate their motivation to copulate (Van Belle et al., 2009): these were approaches to males and sexual presentations to males. Once consortship was initiated, we also recorded copulation calls uttered during copulation. Male sexual behaviours directed toward females were used to assess male responses to females' signals; we recorded approaches by males, holding, mounts (attempts, non-ejaculatory mounts, ejaculatory mounts), and inspections of the anogenital area by using both direct observations and video-recording. Olfactory inspections, copulation calls and mounts were also recorded by ad libitum observations. See Table 1 for the description of behavioural items recorded by all occurrences, focal and ad libitum sampling.

The total daily observation time was identical between days. A total of $306 \mathrm{~h}$ of observation ( $25.5 \mathrm{~h}$ per female on average) were collected over our study period. Focal samples were evenly distributed across days and weeks for all females and were carried out between 14:00 and 18:00 on weekdays and between 8:30 and 12:30 on Saturdays.

\section{Table 1.}

Ethogram of sexual behaviours collected (modified from Rigaill et al., 2013).

$\begin{array}{ll}\begin{array}{l}\text { Female behaviours } \\ \text { Approaches } \\ \text { Sexual presentations }\end{array} & \begin{array}{l}\text { Female moves close }(<1 \text { arm distance) to a male } \\ \text { Female directs her anogenital area toward a male, the tail is generally } \\ \text { raised to expose the sexual swelling } \\ \text { Female utters a particular vocalization during the last stage of a mount }\end{array} \\ \text { Male behaviours } & \text { Male moves close (<1 arm distance) or in contact with a female } \\ \text { Approaches } & \text { Male grabs a female's hips, generally observed just before mating } \\ \text { Holding behaviours } & \text { Male mounts a female, without intromission } \\ \text { Mounts: } & \text { Male mounts a female, with intromission but without ejaculation (i.e., } \\ \text { Attempts } & \text { unsuccessful) } \\ \text { Non-ejaculatory mounts } & \text { Male mounts a female, with intromission and ejaculation (i.e., } \\ \text { Ejaculatory mounts } & \text { successful) } \\ \text { Deliberate placing of the nostrils within } 5 \text { cm of a female's anogenital } \\ \text { area and sniffs female's anogenital area } \\ \text { Male touches the female's anogenital area with his finger, or pinches } \\ \text { the swelling to test the turgidity of the swelling }\end{array}$

*During the sampling session we will score manually the 'turgidity of the swelling', scoring 0 (flaccid) to 3 (fully turgid). 


\subsection{Reproductive parameters}

We determined six distinct phases of the menstrual cycle (menstruation, postmenstrual flat, moderate genital swelling, large genital swelling, deflating swelling, full detumescence) and defined the fertile window (including the ovulation period) of each female by combining records of morphological changes in the anogenital area and the cytological evaluation of vaginal swabs. Observations of the anogenital sexual swelling were used as a measure of sexual cycle phases, while genital cytology (i.e. cell populations change abruptly right after ovulation) was used as an objective criterion to measure the ovulation timing and to assess the regularity of the receptive cycle.

\subsubsection{Observations of morphological changes in the anogenital area}

During the follicular phase of the menstrual cycle, the olive baboon anogenital area increases in turgescence due to estrogenic stimulation (Dixson, 1998). Ovulation most commonly occurs during the last few days of maximal tumescence, typically two days before the swelling subsides (reviewed in Rigaill et al., 2013). In order to comprehensively register these transformations, daily records of morphological changes in the anogenital area and menstruation were made over the study period. In addition, each female's reproductive history was known from colony records.

\subsubsection{Genital cytology sampling}

Cytological evaluation of vaginal cells provides a reliable determination of the exact stage of the baboon menstrual cycle (Honoré \& Tardif, 2009).

We collected vaginal swabs from study subjects five days per week, Monday to Friday (i.e., we were not allowed to collect samples during weekends by the SdP CNRS management team due to lack of keepers on site and thus related safety issues). We collected a full series of slides over the period with moderate, large and deflating swellings for 31 of 38 cycles. For the remaining seven cycles, we missed one sampling day during the large swelling period, when ovulation is most likely.

In order to collect samples, we gently inserted a cotton-tipped swab inside the vulva, then we rotated the end through 3 revolutions, to pick up sufficient vaginal cells for cytological evaluation, before gently withdrawing the swab. We prepared the smear immediately by rolling the cotton tip along the length of a glass microscope slide and fixed it using a spray fixative (CytoRAL). 
We prepared and stained vaginal smear slides using commercially available kits (RAL Diagnostics) at the Laboratory of Molecular Biology (SdP CNRS), and evaluated slides using LAS (4.3) software in the Department of Biosciences, Durham University. The Kit Diagnoestrus ${ }^{\circledR}$ is a commercial simplified Harris-Schorr technique for use with vaginal smears. It consists of three rinsing solutions and involves an accurate procedure lasting around $16 \mathrm{~min}$. We stained the smear by following the kit protocol, then dried the slide and applied a coverslip.

Hendrickx \& Kraemer (1969) give an extensive description of the cyclical changes in vaginal epithelial cells through the baboon menstrual cycle. Honoré \& Tardif (2009) and Shambayati (2011) describe the different cell types (superficial, intermediate, parabasal and basal) characteristic of each phase in detail. We detected ovulation based on a sudden decrease in superficial cells with brownish tan granular cytoplasm and, in many instances, by intermenstrual bleeding. The postovulatory phase is marked by the return of leukocytes and mucus, as well as clumped, curled and folded cells and, quite commonly, placard or rosette arrangements of cells.

When we had a full series of slides, we established the exact day of ovulation ( 31 cycles). When we did not have a full series of slides ( 7 cycles) we considered the two days before such abrupt change in vaginal cell populations. We considered the ovulation window as two days, the day of ovulation and the previous one ( 31 cycles with full series of slides available) or the two days before vaginal cell populations changed abruptly (remaining $7 \mathrm{cy}-$ cles without full series of slides available).

\subsection{Statistical analyses}

In order to test the best predictors for the use of copulation calls by female baboons - physiological or social - we conducted a generalized linear mixed model. For this model, we insert the occurrence of copulation calls (absent/present) as our response variable (binary). In addition, we inserted mounting outcome (with three levels: attempt, non-ejaculatory mounting, ejaculatory mounting) and cycle phase (as measured by the phases of the anogenital sexual swelling, with six levels: menstruation, post-menstrual flat, moderate swelling, large swelling, deflating swelling and full detumescence) as two fixed factors. Finally, we inserted female ID and troop ID as random effects in order to act as a control for the disproportional contribution of certain females/troops to the data sample. To run the model, we used $\mathrm{R}$ 
as programming language ( $\mathrm{R}$ Team, 2010) and the function lmer of the Rpackage lme4 (Bates et al., 2008).

\section{Results}

Female subjects in the test troops $(N=12)$ vocalized infrequently $(N=$ 15) during copulation mounts $(N=128,92$ of which with ejaculation). Accordingly, whilst females showed to be motorically able to vocalize (see video at 10.6084/m9.figshare.12687209), they did not do so often, having remained silent in $88.3 \%$ of the copulation mounts on average. In troop 1, four (out of six) females vocalized 14 times $(7,5,1,1)$ in 125 copulation mounts (12 with ejaculation); in troop 2, one (out of three) female vocalized one time during 12 copulation mounts (one with ejaculation); and in troop 3 no female vocalized in six copulations (none with ejaculation).

Genital cytology data (Figure 1) confirmed that females experienced regular receptive cycles, with an average of around three full cycles per female during the study. Genital cytology also determined the ovulatory status of individuals when they were copulating and producing/not producing copulation calls.

Generalized linear mixed models allowed us to directly test the two competing hypotheses about the mechanisms underpinning baboon vocal behaviour during sex: whether ovulation phase or male mounting played a predominant role eliciting copulation calls in our test baboons. Comparison between our full model and the respective reduced model without ovulation phase revealed that ovulation phase had no detectable impact on the performance of the full model (Chi-square test between full vs. reduced model, $\mathrm{df}=5, p=0.979$ ). However, removing mounting outcome from the full model significantly affected the model's performance (Chi-square test between full vs. reduced model, $\mathrm{df}=2, p<0.001$ ).

\section{Discussion}

Our results challenge the premise that the trigger or gauge for female copulation calls in baboons is governed by ovulation and hormonal profiles associated with reproductive receptivity. Copulation calls were averted almost completely in our study troops, in spite of normal female cycling (including during consortships in the fertile periods), which was confirmed through vaginal cytology and observations of morphological changes in the anogenital area. These findings stand in contrast with what has been por- 


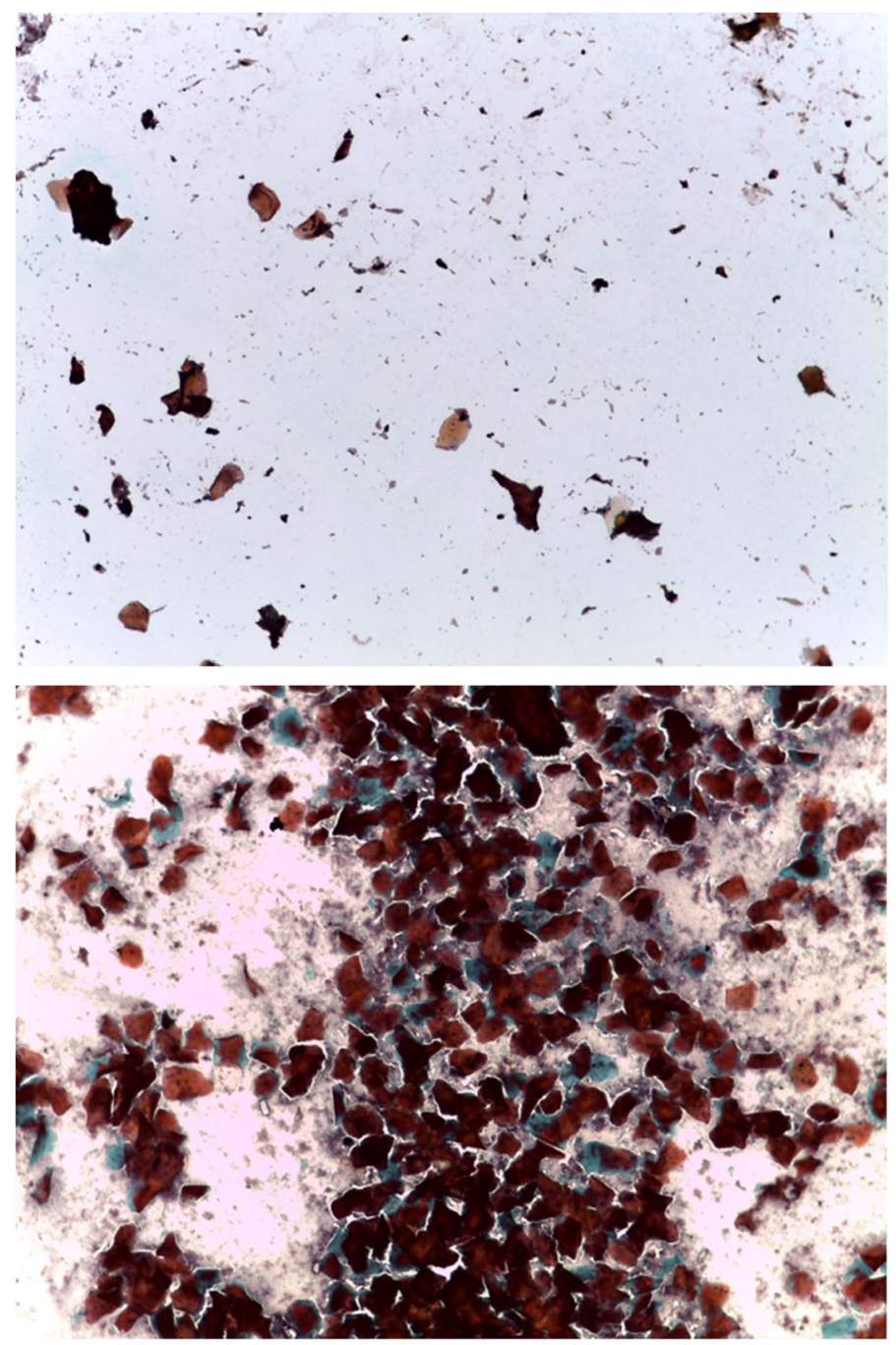

Figure 1. Genital cytology data confirming that females experienced regular receptive cycles, with an average of around three full cycles per female during the study. In comparison to the preovulatory phase (top panel), the postovulatory phase (bottom panel) is marked by the return of leukocytes and mucus, as well as clumped, curled and folded cells and, quite commonly, placard or rosette arrangements of cells.

trayed previously in other baboon species, described as vocalizing during sex (O’Connell \& Cowlishaw, 1994; Henzi, 1996; Semple et al., 2002; Maestripieri et al., 2005). 
Data showed that in our study troops copulation call usage was best predicted by mating outcome, namely male ejaculation. These observations are consistent with the vocal behaviour of other Old World monkeys and great apes, including humans (Nikitopoulos et al., 2004; Pfefferle et al., 2008; Townsend et al., 2008, 2011; Clay \& Zuberbuhler, 2011; Clay et al., 2011; Engelhardt et al., 2011; Townsend \& Zuberbuhler, 2014). The same extent of vocal control use presumed in these species could therefore also be assumed for female olive baboons.

Although the experimental design of this study focuses upon proximate explanations (female reproductive state vs. male ejaculation, with females producing copulation calls more frequently during successful male mating attempts resulting in ejaculation) we suggest further discussion about ultimate explanations for copulation calls (exogenous social factors vs. endogenous physiological factors) as our study did not test such alternative explanations. In particular, we suggest that copulation call use in baboons could be bound by social factors in a higher degree than physiological factors. Baboon copulation calls would probably be best assumed to constitute a socially selected call and to be under voluntary control, even though their occurrence has hitherto been consistent with what would be predicted for a sexually selected signal under reflex response mechanisms. However, we recognize that the physiological and social mechanisms mediating copulation calls in primates are not necessarily mutually exclusive. As suggested by other authors (e.g., Hauser, 1990; Townsend et al., 2008) the intromission of the male may incite an orgasmic response that triggers a vocal response from females. Given that male ejaculation was the best predictor of female calling, it may be that this ejaculation response triggers a physiological response in females. This therefore would lead to copulation calls being both socially and physiologically mediated.

We also recognize that data were collected from a captive facility which may carry significant drawbacks. Firstly, the dataset may not fully simulate the normal social and ecological conditions that individuals are exposed to and that have shaped behaviour in the wild. As a consequence of this, our findings could be a by-product of captivity and hence the evolutionary relevance and the adaptive function of the call would be less clear. Secondly, the study was conducted on three one-male multi-female groups of baboons housed in multiple neighboring enclosures. Although females had access to males living in neighboring enclosures, including sexual presentations and 
interactions with them, it is possible that females did not consider such neighboring males as potential full mates. Therefore, as several studies have posited that copulation calls function to communicate with other potential male mates within a given group (reviewed in Pradhan et al., 2006) then patterns of copulation calls may be masked by our study sample, which restricts full mating opportunities to a single male.

However, even in such cases, these drawbacks would not undermine the fact that we found that female baboons have control over their vocal behaviour. In addition, we have found a significantly lower calling rate in this captive context than in other studies on olive baboons (e.g., females call $47.4 \%$ of the time - Rigaill et al., 2013; call $62.0 \%$ of the time - Bercovitch, 1985). The captive context of our observational study, therefore, may have played an important role in informing these copulation calls, which would contribute to demonstrate the role that social context plays in the expression of these mating-associated vocalizations.

Interestingly, Rigaill and colleagues (2013) found that fine-scale variation in sexual swelling size, female sexual behavior and copulation call rates could advertise the beginning of the fertile phase in captive olive baboons. However, they estimated the baboon fertile period from the date of swelling detumescence by using only observations of the anogenital sexual swelling, whilst we used records of morphological changes in the anogenital area to measure the sexual cycle phases and then genital cytology to detect the ovulation window. Histological data provide more accurate and objective information as a means of pinpointing the fertile period and ovulatory phase, which possibly accounts for the difference in findings between the only two studies using discreet measures of female ovulation to examine the relationship between fertility and copulation calls in olive baboons.

Future research may enlighten the factors guiding female choice with regards to their reproductive strategies. These studies may resort to naturalistic alternations in troop composition, mimicking some of the regular changes that occur in nature, both in baboons in particular and in non-human primates in general. These social changes may therefore be deployed as means of captive enrichment. These "experiments" can be designed so as to provide insight into how females of highly social primates change reproductive tactics in the light of demographic features of their social environment, including tactics moderated by their strategic vocal use. 
Finally baboons are also preeminent models of human reproductive biology (VandeBerg et al., 2009). However, despite their desirable role in comparative research for sexual aspects of human anatomy, physiology and behaviour, there are marked differences between how females of the two species advertise sexual receptivity. For instance, human females exhibit concealed ovulation and contrast in the use of mating-associated vocalizations. These differences carry potential work on the implications regarding how we understand female baboons' reproductive physiology and how biomedical research uses these animals as study models for human females' sexuality.

\section{Acknowledgements}

This study was funded by a Marie Skłodowska-Curie Intra European Fellowship within the 7th European Commission Framework Programme (Grant Agreement No. 2012-327083) to S.V. This project has also received funding from the Department of Anthropology's Research Fund - Durham University to S.V.

The authors would like to thank Lauren Woodland, for helping with data handling; Paul Hunt and Simeon Johnson, for assisting with cytological evaluation of vaginal smear slides; Romain Lacoste and the members of the CNRS Primatology Station for their warm welcome and enthusiastic help with project management; Esther Clarke for useful discussions about the paper; and Jo Setchell for invaluable supervision to S.V. throughout the project PrimOlf. The authors would also like to thank two anonymous reviewers for their constructive comments and helpful suggestions.

\section{References}

Alberts, S.C., Watts, H. \& Altmann, J. (2003). Queuing and queue jumping: long term patterns of dominance rank and mating success in male savannah baboons. - Anim. Behav. 65: 821-840.

Anoop, K.R. \& Yorzinski, J.L. (2013). Peacock copulation calls attract distant females. Behaviour 150: 61-74.

Bates, D., Maechler, M. \& Dai, B. (2008). lme4: linear mixed-effects models using S4 classes. - R package, R Core Team, Vienna.

Beach, F.A. (1976). Sexual attractivity, proceptivity, and receptivity in female mammals. Horm. Behav. 7: 105-138. 
Bercovitch, F.B. (1985). Reproductive tactics in adult female and adult male olive baboons. - $\mathrm{PhD}$ thesis, University of California, Los Angeles, CA.

Campbell, C., Nair, Y., Maimane, S. \& Nicholson, J. (2007). 'Dying Twice': a multi-level model of the roots of AIDS stigma in two South African communities. - J. Health Psychol. 12: 403-416.

Clay, Z. \& Zuberbuhler, K. (2011). The structure of bonobo copulation calls during reproductive and non-reproductive sex. - Ethology 117: 1158-1169.

Clay, Z., Pika, S., Gruber, T. \& Zuberbuhler, K. (2011). Female bonobos use copulation calls as social signals. - Biol. Lett. 7: 513-516.

Cox, C.J. \& LeBoeuf, B.J. (1977). Female incitation of male competition: a mechanism of mate selection. - Am. Nat. 111: 317-335.

Darwin, C. (1876). Sexual selection in relation to monkeys. - Nature 15: 18-19.

Dixson, A.F. (ed.) (1998). Primate sexuality: comparative studies of the prosimians, monkeys, apes and human beings. - Oxford University Press, New York, NY.

Engelhardt, A., Fischer, J., Neumann, C., Pfeifer, J.B. \& Heistermann, M. (2011). Information content of female copulation calls in wild long-tailed macaques (Macaca fascicularis). Behav. Ecol. Sociobiol. 66: 121-134.

Fedorka, K. \& Mousseau, T. (2001). Material and genetic benefits of female multiple mating and polyandry. - Anim. Behav. 64: 361-367.

Hamilton, J. \& Arrowood, P.C. (1978). Copulatory vocalizations of chacma baboons (Papio ursinus), gibbons (Hylobates hoolock) and humans. - Science 200: 1406-1407.

Hauser, M.D. (1990). Do chimpanzee copulatory calls incite male-male competition? Anim. Behav. 39: 596-597.

Hendrickx, A.G. \& Kraemer, D.C. (1969). Observation of the menstrual cycle, optimal mating time, and preimplantation embryos of the baboon. - J. Reprod. Fert., Suppl. 6: 119-128.

Henzi, P.S. (1996). Copulation calls and paternity in chacma baboons. - Anim. Behav. 51: 233-234.

Honoré, E.K. \& Tardif, S.D. (2009). Reproductive biology of baboons. - In: The baboon in biomedical research (VandeBerg, J.L., Williams-Blangero, S. \& Tardif, S.D., eds). Springer, New York, NY, p. 89-110.

Janik, V.M. \& Slater, P.J.B. (1997). Vocal learning in mammals. - Adv. Stud. Behav. 26: 59-99.

Løvlie, H., Zidar, J. \& Berneheim, C. (2014). A cry for help: female distress calling during copulation is context dependent. - Anim. Behav. 92: 151-157.

Maestripieri, D., Leoni, M., Raza, S.S., Hirsch, E.J. \& Whitham, J.C. (2005). Female copulation calls in Guinea baboons: evidence for postcopulatory female choice? - Int. J. Primatol. 26: 737-758.

Maestripieri, D. \& Roney, J.R. (2005). Primate copulation calls and postcopulatory female choice. - Behav. Ecol. 16: 106-113.

Moos Heilen, R. \& Sossinka, R. (1990). The influence of oestrus on the vocalization of female gelada baboons (Theropithecus gelada). — Ethology 84: 35-46. 
Nikitopoulos, E., Arnhem, E., van Hooff, J.A.R.A.M. \& Sterck, E.H.M. (2004). Influence of female copulation calls on male sexual behavior in captive Macaca fascicularis. - Int. J. Primatol. 25: 659-677.

Nitsch, F., Stueckle, S., Stahl, D. \& Zinner, D. (2011). Copulation patterns in captive hamadryas baboons: a quantitative analysis. — Primates 52: 373-383.

O'Connell, S.M. \& Cowlishaw, G. (1994). Infanticide avoidance, sperm competition and mate choice: the function of copulation calls in female baboons. - Anim. Behav. 48: 687-694.

Pfefferle, D., Brauch, K., Heistermann, M., Hodges, J.K. \& Fischer, J. (2008). Female Barbary macaque (Macaca sylvanus) copulation calls do not reveal the fertile phase but influence mating outcome. - Proc. Roy. Soc. Lond. B: Biol. Sci. 275: 571-578.

Pizzari, T. (2001). Indirect partner choice through manipulation of male behaviour by female fowl, Gallus gallus domesticus. — Proc. Roy. Soc. Lond. B: Biol. Sci. 268: 181-186.

Poole, J. (1989). Mate guarding, reproductive success and female choice in African elephants. - Anim. Behav. 37: 842-849.

Poole, J.H., Payne, K., Langbauer, W.R. \& Moss, C.J. (1988). The social contexts of some very low frequency calls of African elephants. - Behav. Ecol. Sociobiol. 22: 385-392.

Pradhan, G.R., Engelhardt, A., van Schaik, C.P. \& Maestripieri, D. (2006). The evolution of female copulation calls in primates: a review and a new model. — Behav. Ecol. Sociobiol. 59: 333-343.

R Team (2010). R: a language and environment for statistical computing. — R Core Team, Vienna.

Racey, P.A., Uchida, T.A., Mori, T., Avery, M.I. \& Fenton, M.B. (1987). Sperm-epithelium relationships in relation to the time of insemination in little brown bats (Myotis lucifugus). — J. Reprod. Fert. 80: 445-454.

Rigaill, L., Higham, J.P., Lee, P.C., Blin, A. \& Garcia, C. (2013). Multimodal sexual signaling and mating behavior in olive baboons (Papio anubis). - Am. J. Primatol. 75: 774-787.

Semple, S. (2001). Individuality and male discrimination of female copulation calls in the yellow baboon. - Anim. Behav. 61: 1023-1028.

Semple, S., McComb, K., Alberts, S. \& Altmann, J. (2002). Information content of female copulation calls in yellow baboons. - Am. J. Primatol. 56: 43-56.

Shambayati, B. (2011). Cytopathology, 1st edn. - Oxford University Press, Oxford.

Silk, J.B., Seyfarth, R.M. \& Cheney, D.L. (2016). Strategic use of affiliative vocalizations by wild female baboons. - PLoS ONE 11: e0163978.

Townsend, S.W., Deschner, T. \& Zuberbuhler, K. (2008). Female chimpanzees use copulation calls flexibly to prevent social competition. — PLoS ONE 3: e2431.

Townsend, S.W., Deschner, T. \& Zuberbuhler, K. (2011). Copulation calls in female chimpanzees (Pan troglodytes schweinfurthii) convey identity but do not accurately reflect fertility. — Int. J. Primatol. 32: 914-923.

Townsend, S.W. \& Zuberbuhler, K. (2014). Audience effects in chimpanzee copulation calls. — Comm. Integr. Biol. 2: 282-284. 
Van Belle, S., Estrada, A., Ziegler, T.E. \& Strier, K.B. (2009). Sexual behavior across ovarian cycles in wild black howler monkeys (Alouatta pigra): male mate guarding and female mate choice. - Am. J. Primatol. 71: 153-164.

VandeBerg, J.L., Williams-Blangero, S. \& Tardif, S.D. (eds) (2009). The baboon in biomedical research. - Springer, New York, NY.

White, N.R., Prasad, M., Barfield, R.J. \& Nyby, J.G. (1998). 40- and 70-kHz vocalizations of mice (Mus musculus) during copulation. - Physiol. Behav. 63: 467-473. 